\title{
Vacuum arc cathode spot parameters from high-resolution luminosity measurements
}

\author{
A. Anders, ${ }^{\text {a) }}$ S. Anders, ${ }^{\text {a) }}$ B. Jüttner, and H. Pursch \\ Zentralinstitut für Elektronenphysik, Hausvogteiplatz 5-7, 0-1086 Berlin, Germany \\ W. Bötticher and H. Lück \\ Institut für Plasmaphysik, Universität Hannover, Callinstrasse 38, W-3000 Hannover I, \\ Germany
}

(Received 7 November 1991; accepted for publication 5 February 1992)

\begin{abstract}
Cathode spots on arc-cleaned copper and molybdenum electrodes in vacuum were studied by fast image converter framing and streak camcra photography with high temporal and spatial resolution. The frame exposure time was $20 \mathrm{~ns}$ and the interframe period was $200 \mathrm{~ns}$; the streak sweep time was between $200 \mathrm{~ns}$ and $1 \mu \mathrm{s}$. Spatial structures with a resolution of $5 \mu \mathrm{m}$ could be determined by observing the spot movement with a small slit at the streak camera and a high sweep speed. Strong fluctuations of the light emission of the spot were found with characteristic times of 50-100 ns. When the spot moved out of the slit field of view a stepwise decrease occurred in the measured light, indicating an internal substructure of the spot with distances between fragments less than $10 \mu \mathrm{m}$ and even smaller fragment diameters. The current per fragment was estimated to be $20-40 \mathrm{~A}$. The frames confirm the short time constants of the spot. From frame to frame a spot motion was observed in most cases, yielding spot residence times $<200$ ns.
\end{abstract}

\section{INTRODUCTION}

The current flow into a cold arc cathode in vacuum is concentrated in small mobile spots. Structure, size, and physical parameters of these spots are still controversial. Evaluation of the luminous phenomenon (optical observation) yields typical diameters of about $100 \mu \mathrm{m},{ }^{1}$ leading to current densities not higher than $10^{9} \mathrm{~A} / \mathrm{m}^{2}$, whereas erosion traces (craters) at the cathode show much smaller dimensions of the active surface zone and suggest current densities of $10^{12} \mathrm{~A} / \mathrm{m}^{2}$ or even higher. ${ }^{2,3}$

Another subject of dispute is the time constant of spot formation. In optical studies this is often defined as the time between subsequent spot splitting, ${ }^{4}$ amounting to 1$10 \mu \mathrm{s}$. Apart from the frequent confusion of spot formation time with spot lifetime, the optical values are rather different from crater formation times which lie in the range of 10-100 ns and may reach values down to a few ns. ${ }^{5-7}$ In contrast to this, Rakhovsky ${ }^{8}$ and Nazarov, Rakhovsky, and Zhurbenko, ${ }^{9,10}$ were not able to find temporal variations of spot brightness in streaks of $<1 \mu$ s duration.

An essential drawback of the crater studies is their postmortem character, whereas optical measurements refer to the living object. Therefore, it is valuable to examine the latter in more detail. There are few papers that consider the optical effect of spot dynamics and plasma expansion. Djakov and Holmes ${ }^{11}$ established spot splitting above a certain current (with $\mathrm{Cu}$, at about $75 \mathrm{~A}$ ). The same authors ${ }^{12}$ found that a single $\mathrm{Cu}$ spot may consist of mobile internal fragments. The luminous objects were called fragments if their distance apart was less than $0.5 \mathrm{~mm}$, otherwise they were taken as separated spots.

\footnotetext{
a) Present address: Lawrence Berkeley Laboratory, University of California, Berkeley, California 94720 .
}

According to these authors the densitometer trace of a fragment consists of a flat top with broad wings, the top belonging to the active surface zone and the wings to the expanding plasma. Extrapolating the trace of the luminosity to the flat top, in certain cases the optical size reduced down to a most probable area of $(5-10) \times 10^{-10} \mathrm{~m}^{2}$, for a corresponding diameter of $13-18 \mu \mathrm{m}$.

Microphotographs of $\mathrm{Cu}$ arc spots can show a size below $50 \mu \mathrm{m}$ even without such an extrapolation if the effects of spot dynamics are small. Hantzsche and Jüttner ${ }^{3}$ found smallest values of $20-40 \mu \mathrm{m}$. However, such simple observations do not yet consider the complex radiation processes in the expanding spot plasma-up to now there has been no thorough analysis of them. A completely ignored problem is the fact that the visible radiation stems from excited atoms in most cases, whereas the degree of ionization of the spot plasma is close to $1 .{ }^{13}$ It is known that the spatial ion distribution is different from the spatial atom distribution, resulting in different profiles of ionic and atomic radiation. Thus the distribution of the spectrally integrated light cannot be used for the determination of the current density. This is discussed elsewhere. ${ }^{14}$

Finally, the cleanliness of the cathode surface has a decisive influence on the structure of the arc erosion track.

Contaminents strongly enhance the spot dynamics, possibly leading to a large luminous area with little light modulation. ${ }^{15} \mathrm{~A}$ reliable method for removing the contaminents is the arc itself. ${ }^{16}$ Therefore, it is advantageous to start the experiments only after prolonged arcing in vacuum. This was done in the work of Djakov and Holmes ${ }^{11,12}$ and Hantzsche and Jüttner. ${ }^{3}$ Typically, it was not done (or not sufficiently) in the publications that claim a spot size $>100 \mu \mathrm{m}$.

The present paper reports a detailed study of the lumi- 


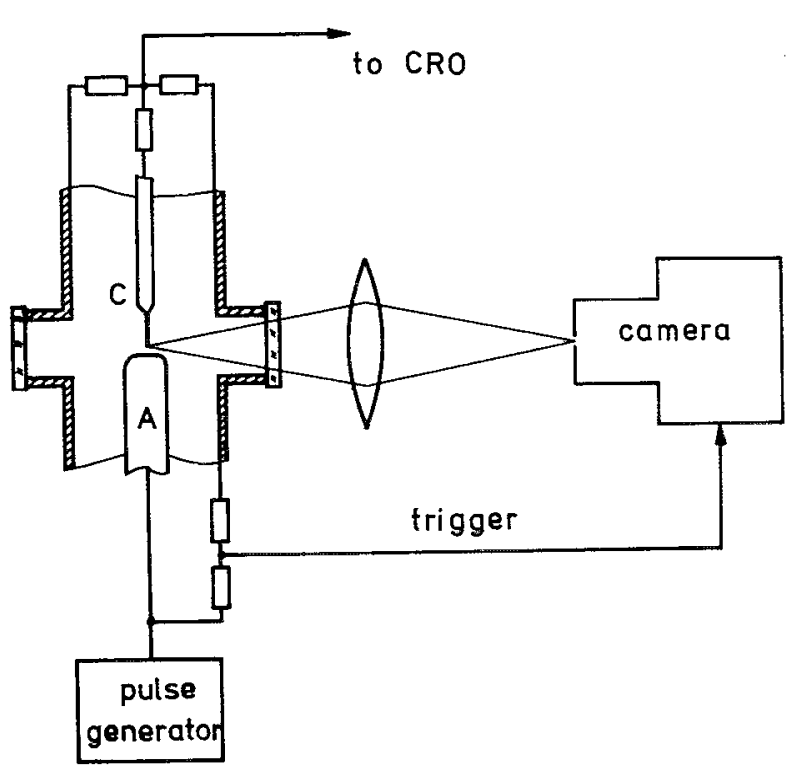

FIG. 1. Experimental setup. A: anode; C: cathode.

nous spot on arc-cleaned surfaces in vacuum, exploiting the effects of spot dynamics to enhance the spatial resolution of the optical measurements.

\section{EXPERIMENT}

Cathode spots of pulsed discharges between a needle cathode and a rod anode were investigated by fast image converter frame and streak cameras. The cathode was a thin wire made of copper or molybdenum (diameter 280 and $200 \mu \mathrm{m}$, respectively); the anode was made of copper. The experimental setup is shown schematically in Fig. 1. The electrode system formed a coaxial line with $50 \Omega$ impedance.

An enlarged image of the electrodes (magnification $2.5 \times$ ) was projected onto the entrance plane of one of the cameras. For streak measurements, a narrow slit was used in the entrance plane, and its projection into the plane of the electrodes defines an "effective slit width" (Fig. 2). If

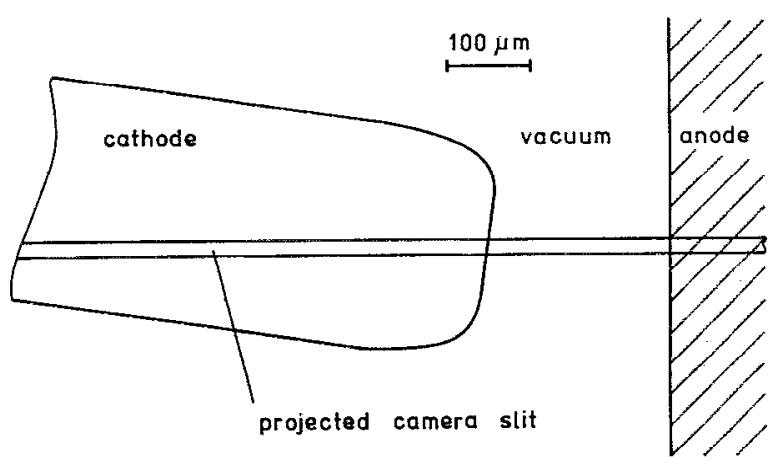

FIG. 2. Electrode geometry with camera entrance slit determining the field of view.

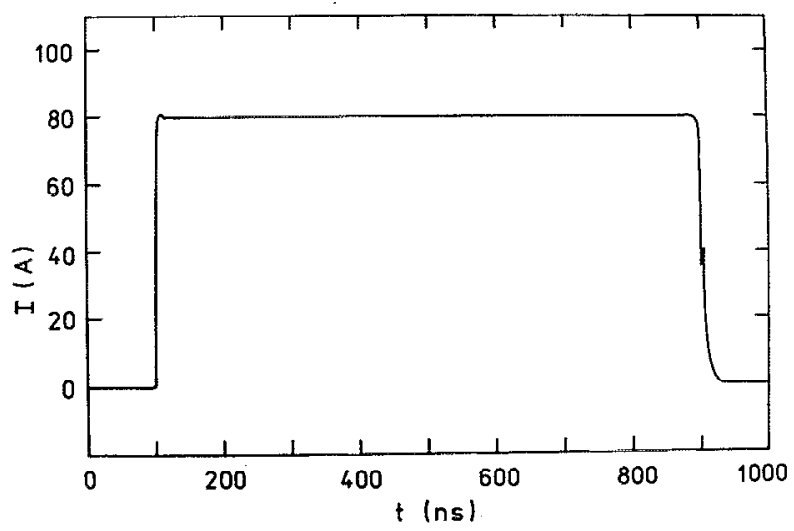

FIG. 3. Oscillogram of the discharge current $I$.

not otherwise indicated, we used a standard effective slit width of $20 \mu \mathrm{m}$.

The arc spots were ignited at the top of the cathode by a high-voltage breakdown. The discharges were fed by a 50 $\Omega$ coaxial cable generator charged up to $5-20 \mathrm{kV}$. The current (50-200 A) was monitored for each discharge by a digital storage oscilloscope, indicating a rise time of $5 \mathrm{~ns}$ and a discharge time of $800 \mathrm{~ns}$ (Fig. 3). The cameras werc triggered by a signal from the voltage divider (see Fig. 1). Before measuring, the electrodes were cleaned by prolonged arcing in oil-vapor-free vacuum with a base pressure below $10^{-6} \mathrm{~Pa}$.

Due to the ignition of the discharge by high-voltage breakdown, anodic vapor is emitted at the beginning of the discharge. As shown by framing camera photography (see Sec. III A) and dye laser absorption measurements, ${ }^{17}$ the production of anodic vapor ceased after $10-30 \mathrm{~ns}$, and a purely cathodic discharge remained. All measurements presented in this paper refer to times $>100 \mathrm{~ns}$ after ignition (except Sec. III B).

A further peculiarity is the magnetic field of the arc current flowing in the cathode wire, which can be estimated to 30-150 mT depending on the current and the diameter of the cathode. Magnetic fields of this value can influence the spot motion considerably. It is difficult to determine the exact geometry of the magnetic ficld but it is to be expected that the spot motion is not a pure random walk as it would be without magnetic field.

\section{RESULTS}

\section{A. Spot framing photography}

The image converter camera (IMACON 792, Hadland Photonics) was used for high-speed framing observations. The cathode was copper and the current was kept constant at 100 A. 200 ns after ignition of the arc the framing camera started to take frames with an exposure time of $20 \mathrm{~ns}$ and an interframe period of $200 \mathrm{~ns}$ (dark period $180 \mathrm{~ns}$ ). In most cases only one cathode spot was present; in a few cases we observed two. Typical framing photographs are shown in Fig. 4. 

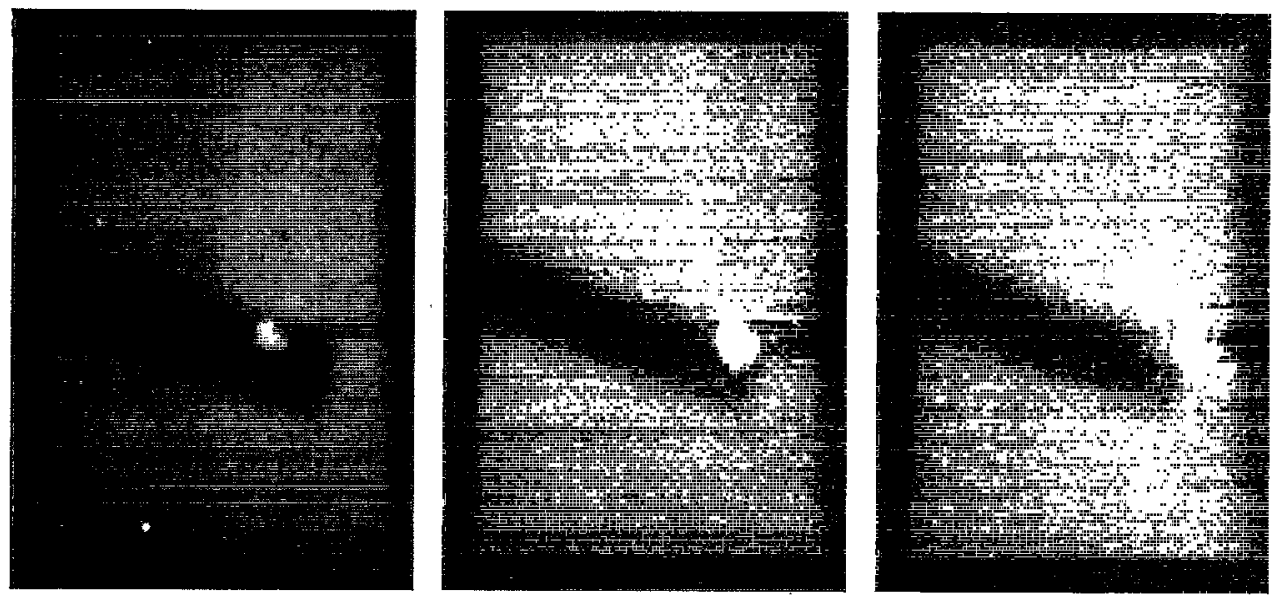

FIG. 4. Subsequent framing camera photographs of the cathode spot, $I$ $=100 \mathrm{~A}$, Cu cathode, interframe period $200 \mathrm{~ns}$.

It is not possible to determine the diffusion constant $D$ of the random walk (see Sec. IV C) because the exposure time is comparable with the spot residence time, but the diffusion law of the motion is only valid for times much in excess of the elementary step time. Furthermore, the expected mean displacement of the spot in the observation time of maximum $800 \mathrm{~ns}$ is about $40 \mu \mathrm{m}$ [the mean displacement $s$ in observation time $t$ is given by $s^{2} / t \simeq 2$ $\times 10^{-3} \mathrm{~m}^{2} / \mathrm{s}$ (Ref. 7)], and is therefore slightly greater than the spatial resolution of $25 \mu \mathrm{m}$ of our optical system. The measured mean spot displacement is about $50-80 \mu \mathrm{m}$, and it is larger in the direction parallel to the wire than perpendicular. This is an indication that the magnetic field of the spot current plays a role, since the discharge geometry is only symmetric if the spot is located exactly at the cathode top.

Nevertheless, several conclusions can be drawn from the framing photography. A spot motion from frame to frame is visible in nearly all of our observations. This means that the residence time of the spot is less than 200 ns. In some cases, the total spot displacement is $200-400$ $\mu \mathrm{m}$ in $800 \mathrm{~ns}$, yielding spot velocities of $v=250-500 \mathrm{~m} / \mathrm{s}$. This value is very high. Assuming a spot displacement in chains of overlapping craters [visible from scanning electron microscopy (SEM) pictures of the cathode after exposure; see Sec. III D] and a mean crater diameter $d$ of about $10-15 \mu \mathrm{m}$, the spot residence time is $\tau \cong d / v \cong 20-60$ ns.

\section{B. Location of subsequent short discharges}

Reducing the arc pulse length to 13-25 ns and the gap distance to values $<20 \mu \mathrm{m}$, the displacement from shot to shot was studied by observing the cathode with a microscope and measuring the displacement along one coordinate (parallel to the surface). It was found that the spots were ignited in the vicinity of their predecessors in spite of the fact that several seconds elapsed between successive shots. Integrated photographs of a number $N$ of superimposed discharges were taken. The total one-dimensional spot displacement $\Delta y$ during these discharges was averaged over 10-20 runs. Figure 5 shows the averaged values $\overline{\Delta y}$ as a function of $N$. It can be seen that the displacement $\overline{\Delta y}$ is random, $\overline{\Delta y} \sim N^{1 / 2}$, as in the case of a random walk. As Fig. 5 indicates, the displacement is insensitive to the pulse duration but increases markedly with the current.

\section{Streak photography of the cathode spot}

For more detailed measurements, a Hamamatsu streak camera (C 1155) was used. The streak was recorded photographically and decoded by a computerized microphotometer. Taking into account the statistical nature of cathode spots, more than 1000 single-shot discharges were recorded. Figures 6-9 show typical traces of the brightness along the center of a streak. These data show a strong modulation that can have two reasons: temporal fluctuations and spot motion.

Due to their movement the spots may appear and dis-

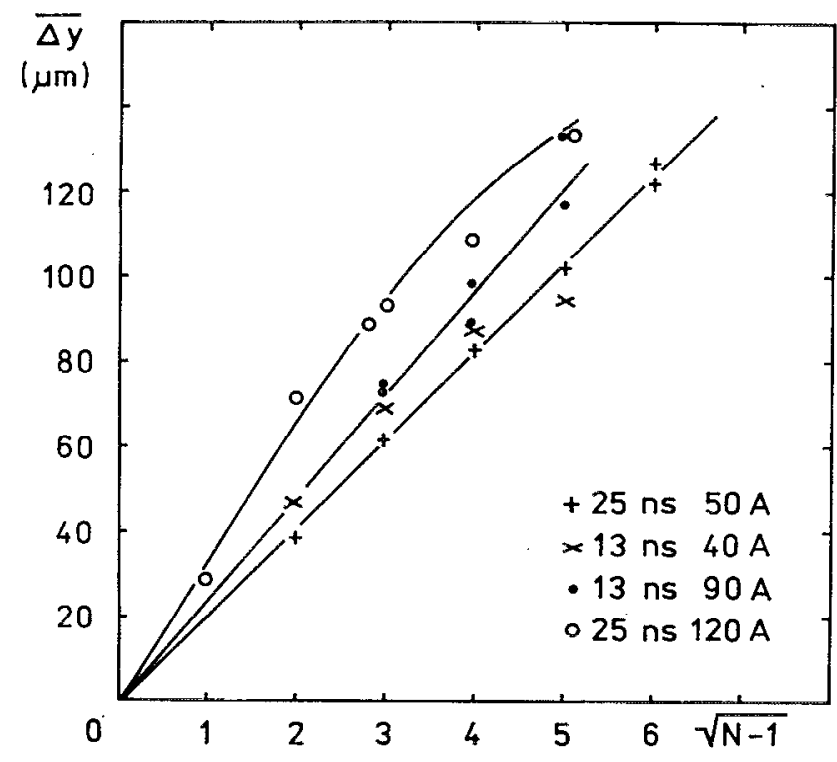

FIG. 5. Average displacement $\overline{\Delta y}$ of spots when superimposing a number $N$ of short discharges. $\mathrm{Cu}$ cathode. Pulse duration and discharge current: $25 \mathrm{~ns}, 50 \mathrm{~A}(+) ; 13 \mathrm{~ns}, 40 \mathrm{~A}(X) ; 13 \mathrm{~ns}, 90 \mathrm{~A}$ (points); $25 \mathrm{~ns}, 120 \mathrm{~A}$ (O). 


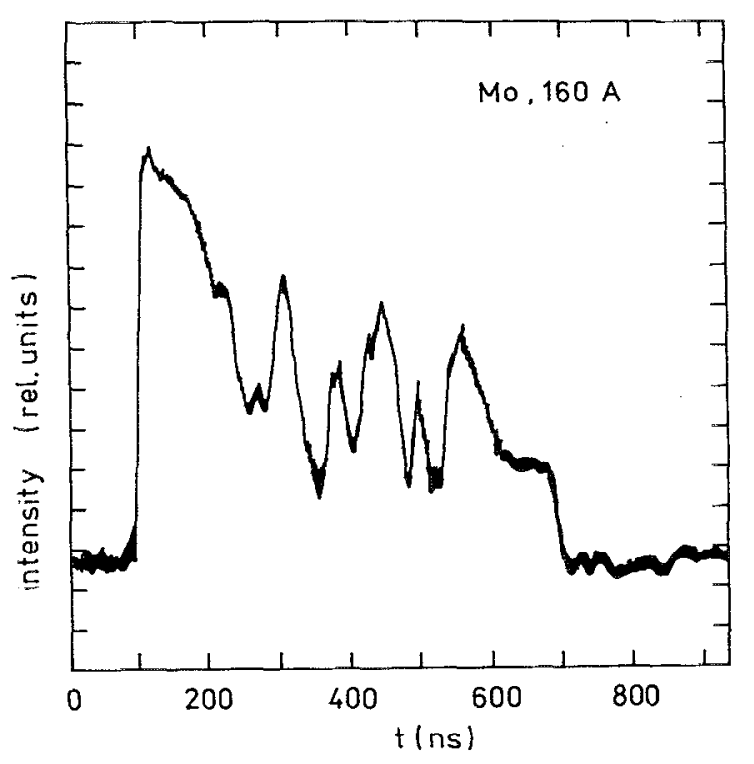

FIG. 6. Luminosity along a streak of a Mo spot, $160 \mathrm{~A}$.

appear in the viewing section. Figure 9 indicates that one or several spots entered the field of view at $t \approx 100 \mathrm{~ns}$, and started to leave it at $t \approx 300 \mathrm{~ns}$. An unambiguous sign of movement is the dependence of the residence time of a spot on the effective slit width. This is shown in Fig. 10. Figures 11 and 12 show the probability for a fluctuation due to spot movement across a slit edge as a function of the time interval $t$ between two of such fluctuations.

However, most of the peaks in the streak signal are associated with temporal changes during the residence time of the spot ensemble in the field of view (e.g., Figs. 6 and 8 ). This is demonstrated by plotting the interval between sufficiently large fluctuations against the effective slit

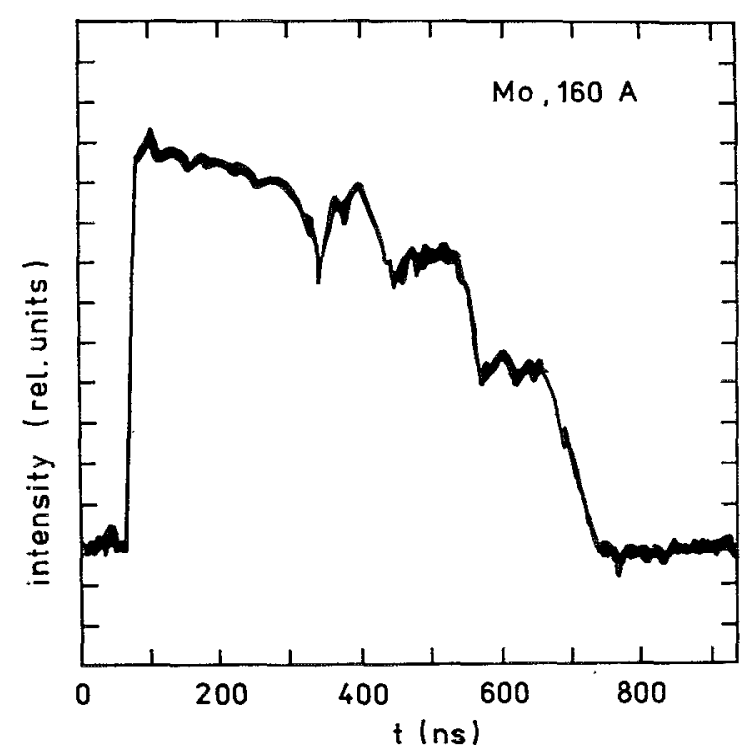

FIG. 7. Luminosity along a streak of a Mo spot, $160 \mathrm{~A}$, showing a stepwise decrease when the spot left the field of view.

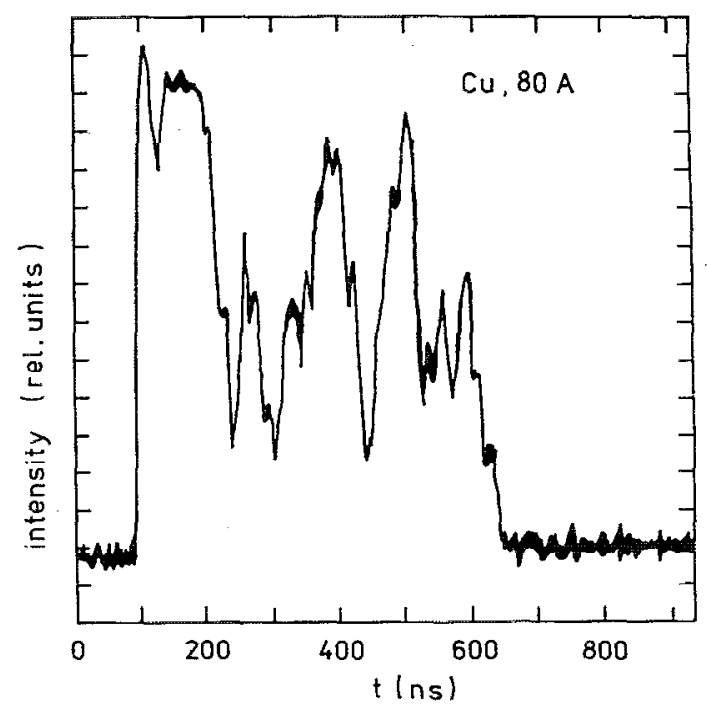

FIG. 8. Luminosity along a streak of a $\mathrm{Cu}$ spot, $80 \mathrm{~A}$.

width. It can be seen from Fig. 13 that there is no dependence on the slit width.

Figure 14 shows that the probability of such fluctuation intervals increases for shorter times. A maximum could exist near $40 \mathrm{~ns}$, but because the amplitude of the fluctuations decreases down to the noise level for intervals $<40 \mathrm{~ns}$, the true maximum could be located at still shorter times. There is no obvious influence of material and current.

\section{Crater size}

After conditioning, the top of the cathode is completely covered with molten structures, so that individual

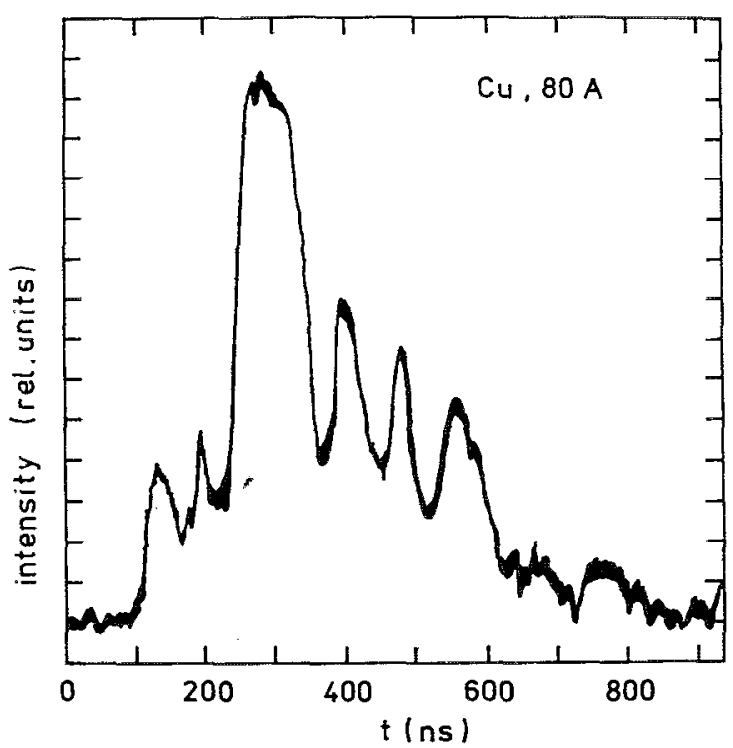

FIG. 9. Luminosity along a streak of a Cu spot, $80 \mathrm{~A}$, indicating appearance and disappearance of a spot in the field of view. 


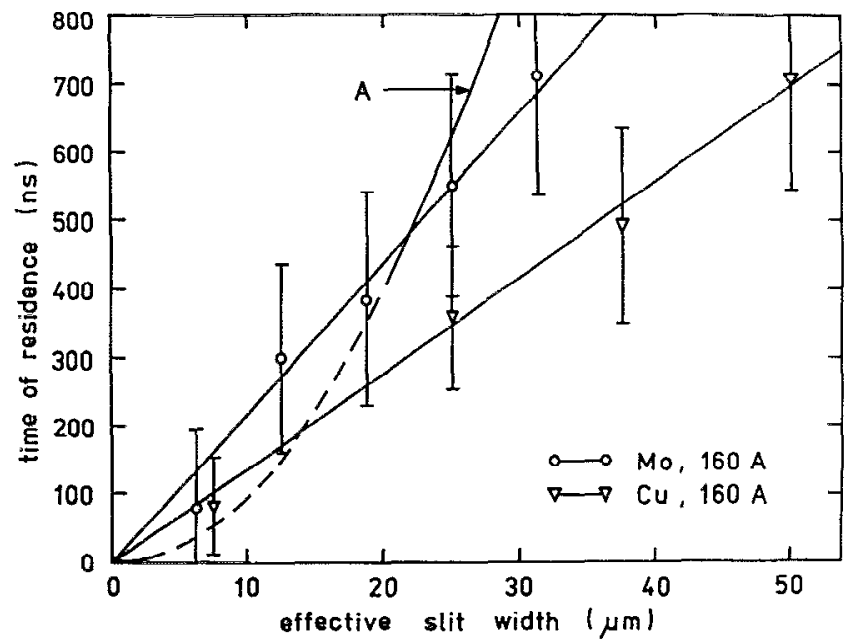

FIG. 10. Dependence of the observation time of a spot in the field of view on the effective slit width for $\mathrm{Mo}(\mathrm{O})$ and $\mathrm{Cu}(\nabla)$. Curve A corresponds to Eq. (2) with $D=10^{-3} \mathrm{~m}^{2} / \mathrm{s}$.

crater chains are difficult to discern. After numerous discharges at $160 \mathrm{~A}$, the $\mathrm{Cu}$ cathodes showed an erosion area up to a distance of $400 \mu \mathrm{m}$ behind the top. Near the boundary of this erosion zone isolated crater traces could be found as, shown in Fig. 15. Besides small single craters (diameter 1-5 $\mu \mathrm{m}$ ), a chain of larger craters (chain width about $20 \mu \mathrm{m}$ ) and a very large crater (diameter $50 \mu \mathrm{m}$ ) are to be seen. The small single craters are probably associated with remnants of the surface contaminents, whereas the crater chain and the large crater are more typical for a clean surface.

Often large craters developed at the end of a crater chain, indicating the combined action of several fragments. Such large molten zones existed also at the eroded area at the top, reaching maximum diameters of $90 \mu \mathrm{m}$.

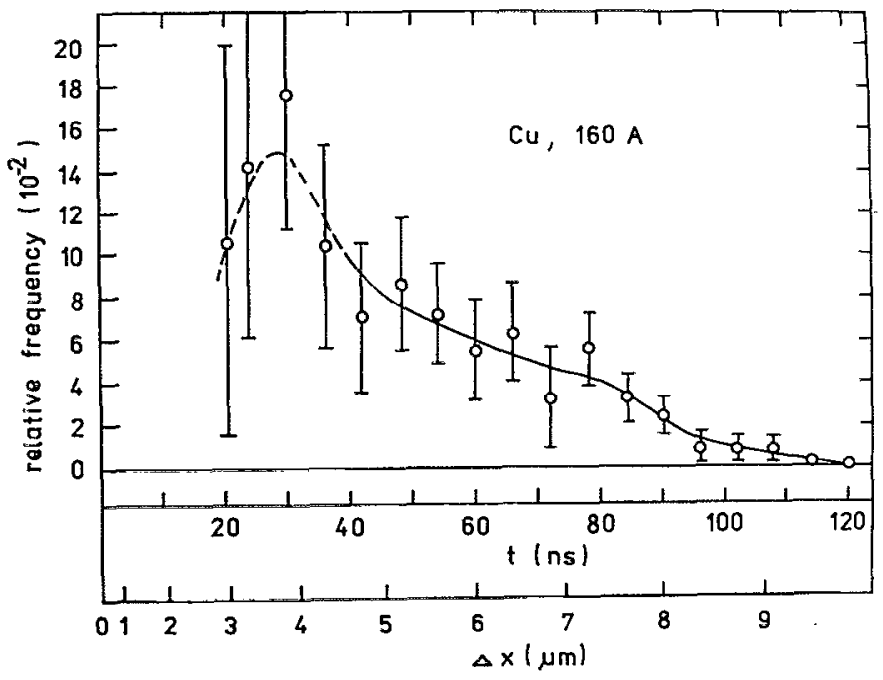

FIG. 11. Probability of time interval $t$ of fluctuations induced by the spot movement; $\mathrm{Cu}, 160 \mathrm{~A}$. The time axis has been converted into a length scale by multiplication by the time-dependent spot velocity.

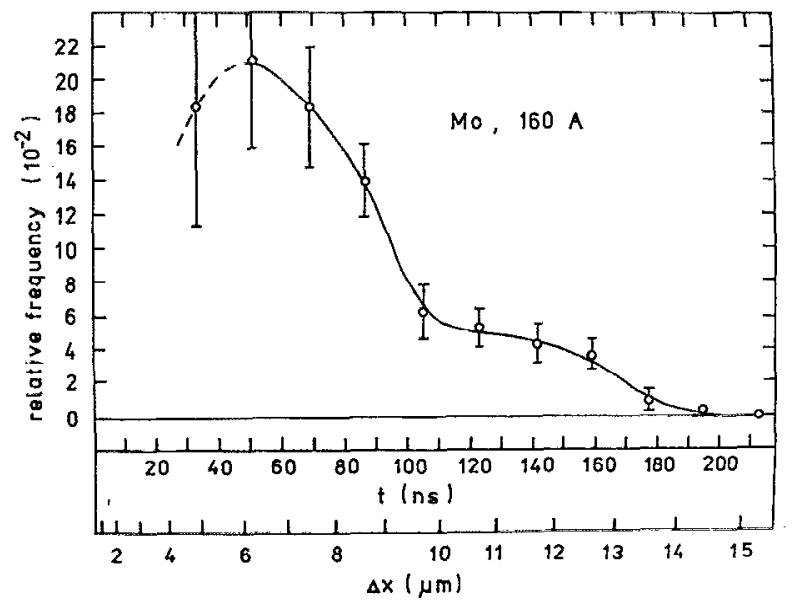

FIG. 12. Probability of time interval $t$ of fluctuations induced by the spot movement; Mo, $160 \mathrm{~A}$. The time axis has been converted into a length scale by multiplication by the time-dependent spot velocity.

Figure 16 shows the distribution of crater diameters from the eroded area near the top of a Cu cathode ( 160 A). The most probable diameter is about $15 \mu \mathrm{m}$, yielding a ratio to the current of $0.09 \mu \mathrm{m} / \mathrm{A}$. This is slightly smaller than the value for dc copper arcs of $0.12 \mu \mathrm{m} / \mathrm{A}$ reported by Daalder ${ }^{18}$ and Jüttner ${ }^{5}$ with currents $<100 \mathrm{~A}$. Apparently, these craters were formed by nearly the entire current; i.e., the probability of spot splitting was small during the discharge duration.

\section{DISCUSSION}

\section{A. Spot structure}

When a spot crosses a slit edge, the change of brightness contains information on spatial structure if the spot velocity is known. Velocity values can be extracted from Fig. 10. Here curve $\mathbf{A}$ corresponds to a purely random movement with $s^{2} / t=10^{-3} \mathrm{~m}^{2} / \mathrm{s}$ (see Sec. IV C). For

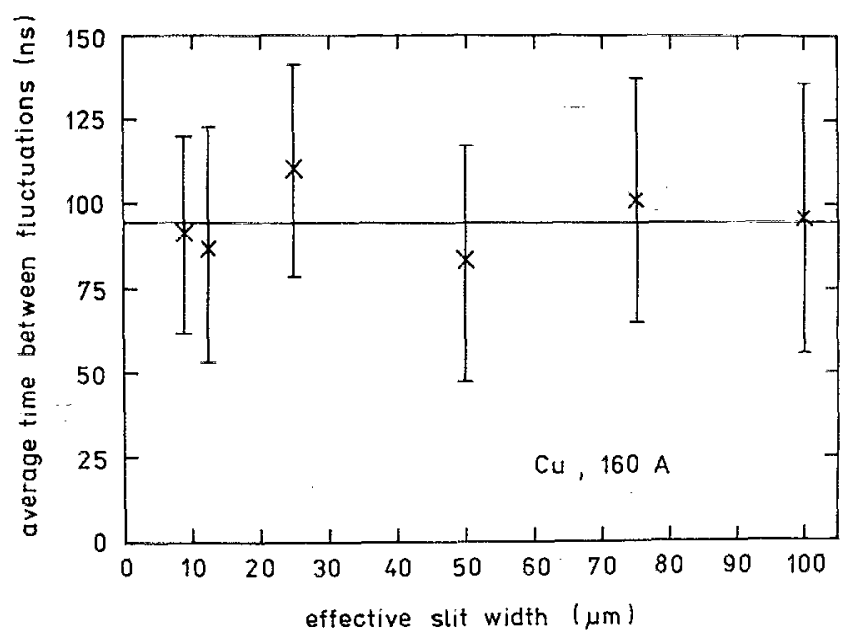

FIG. 13. Interval between well-pronounced fluctuations with large amplitude as a function of "'he effective slit width; $\mathrm{Cu}, 160 \mathrm{~A}$. 


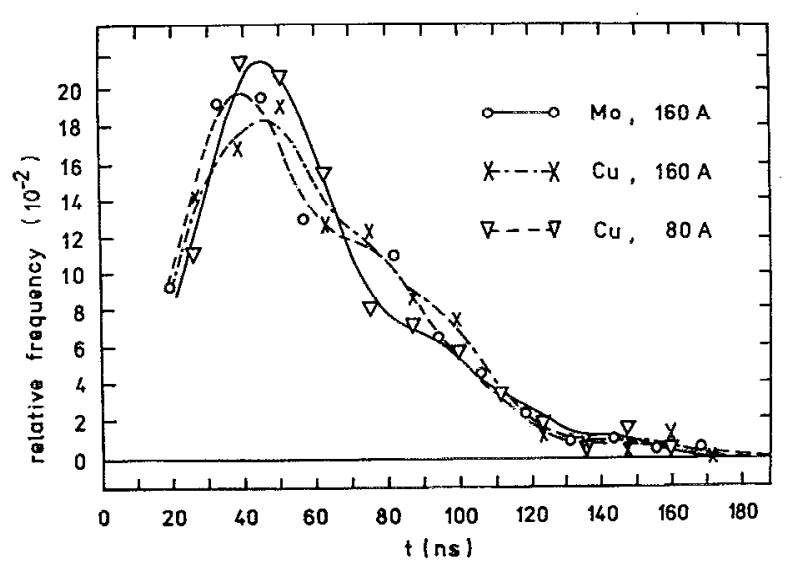

FIG. 14. Probability for the occurrence of a fluctuation interval. $O:$ Mo, $160 \mathrm{~A} ; \mathrm{X}: \mathrm{Cu}, 160 \mathrm{~A} ; \nabla: \mathrm{Cu}, 80 \mathrm{~A}$.

$t>400 \mathrm{~ns}$ the observed displacement is faster than random. This can be explained by the effect of the magnetic field around the cathode wire. In the limit of long times the contribution of the random movement can be neglected, and the directed movement remains. Figure 10 leads then to directed velocities of 36 and $23 \mathrm{~m} / \mathrm{s}$ for $\mathrm{Cu}$ and Mo, respectively.

According to Fig. 9, the signal may increase or decrease when the spot crosses a slit edge. The time for these changes is given by spot size and displacement velocity. In Fig. 9 the signal increases to its maximum within about 150 ns. During this period the spot velocity will be $\leqslant 100$ $\mathrm{m} / \mathrm{s}$, thus the whole luminous object has a size $\leqslant 15 \mu \mathrm{m}$. One obtains a more limited value of the time-dependent velocity when using the result $v_{B}=36 \mathrm{~m} / \mathrm{s}$ from Fig. 10 for

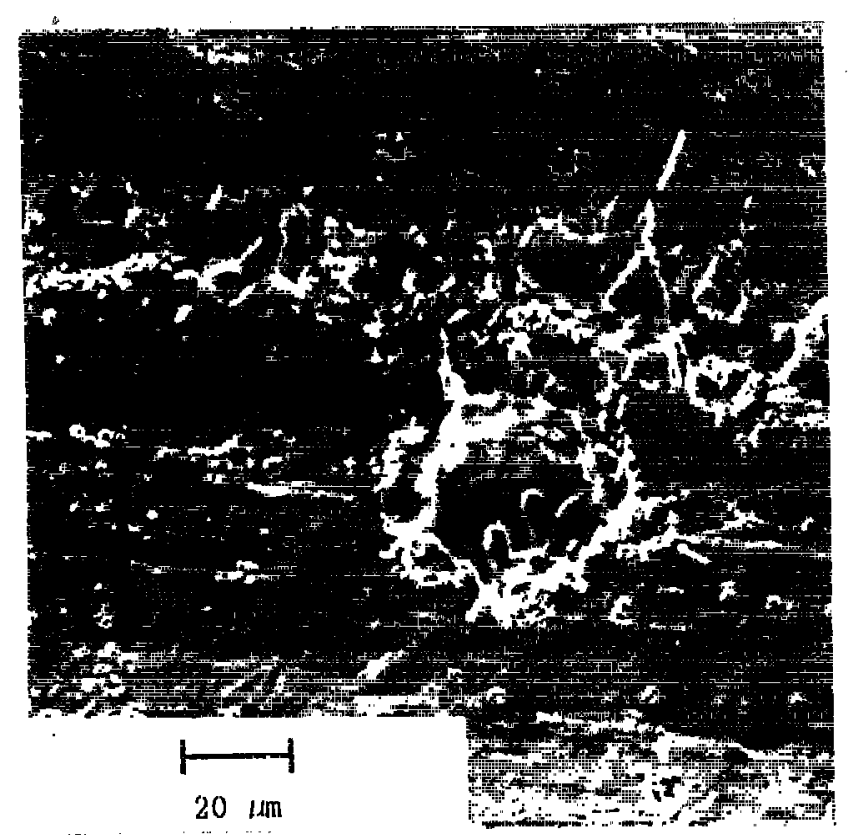

FIG. 15. SEM photograph of the surface of a $\mathrm{Cu}$ cathode near the top after discharges at $160 \mathrm{~A}$.

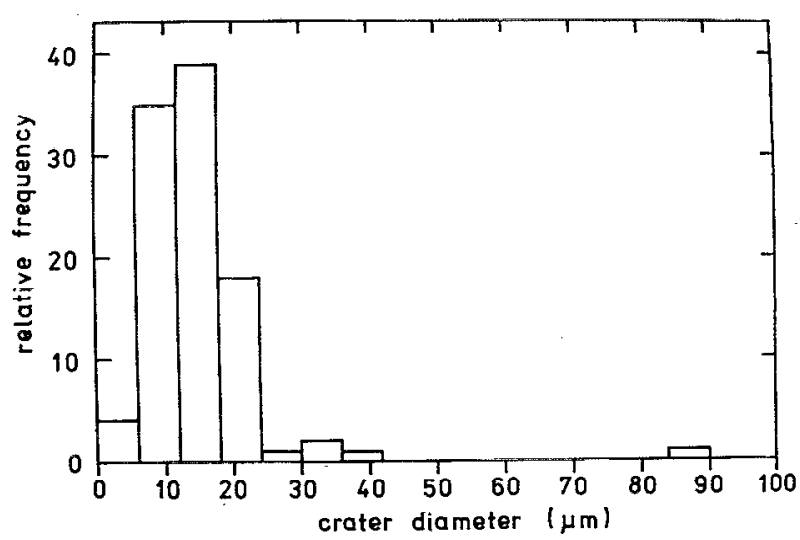

FIG. 16. Distribution of crater diameters for $\mathrm{Cu}, 160 \mathrm{~A}$.

a current of $160 \mathrm{~A}$, where $v_{B}$ is the directed velocity induced by the magnetic field. Since the velocity decreases with current, at $80 \mathrm{~A}$ (Fig. 9) the directed velocity is still less. Adding a random component as suggested by formula (2) in Sec. IV C, with $D=10^{-3} \mathrm{~m}^{2} / \mathrm{s}$ and $t=150 \mathrm{~ns}$, we obtain a total velocity of about $50 \mathrm{~m} / \mathrm{s}$. This reduces the deduced size to a value $<10 \mu \mathrm{m}$, smaller than obtained from spot photographs.

Assuming now that the main peak in Fig. 9 corresponds to a separate structure, the short rising and trailing edges (about $50 \mathrm{~ns}$ ) yield a size of $<7 \mu \mathrm{m}$. So, in selected cases the time scale along the streaks can be converted into a length by multiplying the time by the velocity.

Sometimes the changes occurred in 2-4 steps (Fig. 7). This corresponds to the typical number of internal fragments, ${ }^{12,19}$ so we might interpret the events in Fig. 7 as a successive disappearance of separate spot fragments from the field of view. The width $\Delta t$ of the steps would then be determined by the distance $\Delta x$ between the fragments: $\Delta x$ $=v \Delta t$. Since the trailing edge of the steps in Fig. 7 is smaller than the step width, the fragment size will still be smaller than the distance between them.

In Figs. 11 and 12, the time axis has been converted into a length scale by multiplying it by the time-dependent velocity (Sec. IV C). Obviously, the $\Delta x$ values corresponding to fragment distances are less than $10 \mu \mathrm{m}$. Bearing in mind that we measured only the motion component normal to the slit edge, the given $\Delta x$ values constitute an upper limit. Dividing the total arc current by the observed number of steps, we obtain current per fragment values of $20-40$ A.

The identification of internal spot fragments with distances of only a few $\mu \mathrm{m}$ is an important result. Small inner structures have already been theoretically postulated by Sena, ${ }^{20}$ Emtage, ${ }^{21}$ Harris, ${ }^{22,23}$ Chekalin, ${ }^{24}$ and Puchkarev and Murzakaev. ${ }^{25}$

At higher currents or with contaminated surfaces the fragments can separate to larger distances, leading to an easily observable spot splitting, as shown by Kesaev ${ }^{26}$ and Djakov and Holmes. ${ }^{11,12}$ While the distance between the fragments can be as small as $10 \mu \mathrm{m}$, their diameter is still smaller. This means that the real spot size corresponds to 
the remaining crater. Larger spots can be formed by interactions between the fragments, leading to craters of 50-100 $\mu \mathrm{m}$ diameter. We know of such craters with dc arcs from the literature. ${ }^{27}$ The interesting fact is that they can be formed on a nanosecond time scale. This can be understood by the simultaneous existence of fragments. Generally, the linear dimension of a heated region $L$ is connected with the heating time $\tau_{h}$ by $L^{2} / \tau_{h} \approx$ const. By dividing the heated region into $n$ fragments, the heating time will be reduced by $n^{2}$.

Now the question arises why the spot photographs do not show a bright central region $<10 \mu \mathrm{m}$. This can be explained by insufficient temporal resolution, mainly caused by the rapid dynamics of the internal constituents of a spot. It appears that the fragments are rapidly moving and thus an exposure time of less than $1 \mathrm{~ns}$ seems to be necessary in order to obtain a sharp photograph. However, with our method, i.e., when observing the disappearance of a spot behind a slit edge, the same dynamics helps to discern the fragments. Furthermore, the requirements for the optical system beyond the slit are not so demanding, so that the main emphasis can be put on the sensitivity. The spatial resolution of the camera itself, limiting the spatial resolution in the case of framing observations to $25 \mu \mathrm{m}$, does not play a decisive role in streak measurements. Here the resolution of the image of the electrodes in the plane of the entrance slit of the camera is critical, and can be estimated to be $5 \mu \mathrm{m}$. The small spot size has important consequences for current density and maximum plasma concentration. With a fragment diameter of $5 \mu \mathrm{m}$ and a fragment current of $20 \mathrm{~A}$ we arrive at a current density of $10^{12} \mathrm{~A} / \mathrm{m}^{2}$.

\section{B. Time constants}

In the literature, various quantities have been referred to as time constants. Here we define them more precisely. Listed in order of increasing duration we have the following phenomena.

(i) Crater formation time: According to Daalder, ${ }^{18}$ this is of order $100 \mathrm{~ns}$. Jüttner ${ }^{5}$ found crater formation times of a few ns. One might assume that the formation time of a fragment has a similar value.

(ii) Spot residence time: This is the time for which a spot shows no measurable displacement. Due to the interaction of several fragments, a spot can remain at the same location for longer than the fragment formation time. The residence time determines the velocity of the random movement.

(iii) Interval between two successive events of spot splitting: This is referred to as the spot lifetime by Rakhovskii. ${ }^{1}$ The values reported by this author lie in the range of $1-20 \mu \mathrm{s}$.

(iv) Arc lifetime: This is the time after which a vacuum arc extinguishes, even if all external parameters (electrode distance, external circuit) are kept constant. ${ }^{26,28-30}$ It depends on the cathode material and the arc current, and can reach several seconds.

The present paper deals with processes (i) and (ii). The simple fact that spots can be produced by pulses of 13 ns duration (Sec. III B) demonstrates that fragment and crater formation is faster than the fluctuations reported in Sec. III C. Therefore we assume that the latter indicate the residence time of a spot. Thus, in spite of faster internal processes, the spot may remain $100 \mathrm{~ns}$ or longer at a location. In extreme cases, very large craters can be formed (Fig. 15).

Fluctuations of the burning voltage as measured by Smeets and Schulpen ${ }^{31}$ or by Puchkarev and Murzakaev ${ }^{25}$ can be associated with the residence time, too.

\section{Spot movement}

When the residence time $\tau$ of a spot has elapsed, the ensemble is displaced by an average distance $r$. Without magnetic field the resulting movement is random and the macroscopic displacement $s$ is related to the observation time $t$ by $\overline{s^{2}} / t=D=$ const. The diffusion constant $D$ has been found to be about $10^{-3} \mathrm{~m}^{2} / \mathrm{s}$ for $\mathrm{Cu}$ and $2 \times 10^{-3}$ $\mathrm{m}^{2} / \mathrm{s}$ for Mo. ${ }^{7}$ Since $D=r^{2} / \tau$, one obtains information on either $r$ or $\tau$ if one of these quantities can be measured. From the overlapping nature of crater traces, Jüttner ${ }^{5}$ deduced an elementary step $r$ that corresponds to a crater radius. However, because of the action of the internal fragments, the basic processes of random movement are more complicated than assumed by this author.

The gencral question arises whether the spot moves because its existence conditions have deteriorated at its actual location ${ }^{18}$ or because better conditions are developed elsewhere by the spot itself (e.g., occurrence of crater rims). With clean surfaces, the latter seems more probable. In a spot that has produced a large crater, the individual fragments must have reached equilibrium conditions within a time that is small compared to the residence time, and there is no reason why they should suddenly cease to exist. Also, the experiment described in Sec. III B indicates that spots can promote the ignition of their successors, even after the preceding spot has complctely disappcared.

The random velocity $v_{r}$ depends on the observation time $t$ :

$$
v_{r}=0.5 \sqrt{D / t}
$$

In the presence of a magnetic field the movement becomes more directed (in a retrograde sense). This causes a higher velocity which increases with magnetic field $B$ and current $I$. There is still no theory that yields the retrograde velocity in a reliable manner. Therefore, for the purpose of the present paper we assume a simple superposition of random and dirceted motion:

$$
v(t)=v_{r}+v_{B}=0.5 \sqrt{D / t}+v_{B}
$$

$v_{B}$ being the empirical value of retrograde velocity $\left(v_{B}\right.$ $=36 \mathrm{~m} / \mathrm{s}$ and $23 \mathrm{~m} / \mathrm{s}$ for $\mathrm{Cu}$ and $\mathrm{Mo}$, respectively, $I$ $=160 \mathrm{~A})$. Since $v_{B}$ will not depend on the time $(B, I$ $=$ const), it can be measured if $t$ becomes large.

\section{CONCLUSIONS}

With sufficient spatial and temporal resolution, luminous spot structures can be found that are comparable with 
or smaller than the cathodic craters. They reflect internal fragments of a spot showing intense dynamics on a nanosecond (perhaps subnanosecond) time scale.

Consequently, optical measurements can lead to higher estimates of current density and plasma concentration, at variance to the general opinion in the literature. Accordingly, the elementary times will be shorter than determined up to now by optical methods but in agreement with the results of nanosecond-pulse discharges. To obtain a realistic picture of development and behavior of the internal spot fragments, the temporal and spatial resolution must be increased considerably beyond the present experimental level.

\section{ACKNOWLEDGMENTS}

This work was supported by the Deutsche Forschungsgemeinschaft. We are indebted to Dr. I. G. Brown, Berkeley, Professor E. Hantzsche, Berlin, and Professor J. Mentel, Bochum, for fruitful discussions and advice. We also acknowledge the generous support by Hadland Photonics Ltd., Newhouse Laboratories, Bovingdon, U.K., in particular P. Berkenberg, D. Bowley, and J. Honour.

${ }^{1}$ V. I. Rakhovskii, IEEE Trans. Plasma Sci. PS-4, 81 (1976).

2 J. E. Daalder, IEEE Trans. Power Appar. Syst. PAS-93, 1747 (1974).

${ }^{3}$ E. Hantzsche and B. Jüttner, IEEE Trans. Plasma Sci. PS-13, 230 (1985).

${ }^{4}$ G. A. Lyubimov and V. I. Rakhovskii, Uspekhi Fiz. Nauk 125, 665 (1978) [Sov. Phys. Usp. 21, 693 (1978)].

${ }^{5}$ B. Jüttner, Beitr. Plasmaphys. 19, 25 (1979).

${ }^{6}$ B. Jüttner, Central Institute of Electron Physics, ZIE-Preprint 79-9, Berlin, 1979.

${ }^{7}$ B. Jüttner, J. Phys. D 14, 1265 (1981).

${ }^{8}$ V. I. Rakhovsky, IEEE Trans. Plasma Sci. PS-18, 677 (1990).

${ }^{9}$ S. N. Nazarov, V. I. Rakhovsky, and V. G. Zhurbenko, in Proceedings of the XIIIth International Symposium on Discharges and Electrical
Insulation in Vacuum, Paris, edited by J. M. Buzzi and A. Septier (Les éditions de physique, Paris, 1988), p. 148.

${ }^{10}$ S. N. Nazarov, V. I. Rakhovsky, and V. G. Zhurbenko, IEEE Trans. Plasma Sci. PS-18, 682 (1990).

${ }^{11}$ B. E. Djakov and R. Holmes, J. Phys. D 4, 504 (1971).

${ }^{12}$ B. E. Djakov and R. Holmes, J. Phys. D 7, 569 (1974).

${ }^{13}$ D. T. Tuma, C. L. Chen, and D. K. Davies, J. Appl. Phys. 49, 3821 (1978).

${ }^{14}$ A. Anders, S. Anders, and B. Jüttner, J. Phys. D (to be published).

${ }^{15}$ A. I. Bushik, B. Jüttner, and H. Pursch, Beitr. Plasmaphys. 19, 177 (1979).

${ }^{16} \mathrm{~J}$. Achtert, B. Altrichter, B. Jüttner, P. Pech, H. Pursch, H.-D. Reiner, W. Rohrbeck, P. Siemroth, and H. Wolff, Beitr. Plasmaphys. 17, 419 (1977).

${ }^{17}$ A. Anders, S. Anders, B. Jüttner, W. Bötticher, H. Lück, and G. Schröder, IEEE Trans. Plasma Sci. (to be published).

${ }^{18}$ J. E. Daalder, thesis, Eindhoven University of Technology, 1978.

${ }^{19} \mathrm{~S}$. Anders and B. Jüttner, Beitr. Plasmaphys. 27, 223 (1987)

${ }^{20}$ L. A. Sena, Zhurn. Tekhn. Fiz. 40, 1942 (1970) [Sov. Phys. Tech. Phys. 15, 1513 (1970)].

${ }^{21}$ P. R. Emtage, J. Appl. Phys. 46, 3809 (1975).

${ }^{22}$ L. P. Harris, in Vacuum Arcs, Theory and Application, edited by J. M. Lafferty (Wiley Interscience, New York, 1980), p. 120.

${ }^{23}$ L. P. Harris, IEEE Trans. Plasma Sci. PS-11, 94 (1983).

${ }^{24} \mathrm{E}$. K. Chekalin, in Proceedings of the XVIth International Conference on Phenomena in Ionized Gases, Düsseldorf, edited by W. Bötticher, H. Wenk, and E. Schulz-Gulde (Henkel KG a. A., Düsseldorf, 1983), p. 272.

${ }^{25}$ V. F. Puchkarev and A. M. Murzakaev, J. Phys. D 23, 26 (1990).

${ }^{26}$ I. G. Kesaev, Cathode Processes in Electric Arcs (Nauka, Moscow, 1968) (in Russian).

${ }^{27}$ D. R. Porto, C. W. Kimblin, and D. T. Tuma, J. Appl. Phys. 53, 4740 (1982).

${ }^{28}$ G. A. Farrall, J. M. Lafferty, and J. D. Cobine, IEEE Trans. Commun. Electronics 82, 253 (1963).

${ }^{29}$ B. Jüttner and E. Freund, Beitr. Plasmaphys. 15, 47 (1975).

${ }^{30}$ S. Anders and B. Jüttner, IEEE Trans. Plasma Sci. PS-19, 705 (1991); in Proceedings of the XIVth International Symposium on Discharges and Electrical Insulation in Vacuum, Santa Fe, edited by R. W. Stinnett (Sandia National Laboratory, Albuquerque, 1990), p. 433.

${ }^{31}$ R. P. P. Smeets and F. J. H. Schulpen, J. Phys. D 21, 301 (1988). 